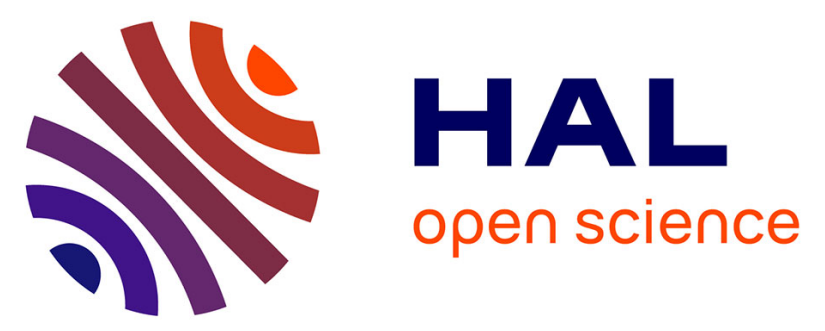

\title{
Lineage tracing of sclerotome cells in amphibian reveals that multipotent somitic cells originate from lateral somitic frontier
}

Bruno Della Gaspera, Alice Mateus, Yannick Andéol, Laure Weill, Frédéric Charbonnier, Christophe Chanoine

\section{To cite this version:}

Bruno Della Gaspera, Alice Mateus, Yannick Andéol, Laure Weill, Frédéric Charbonnier, et al.. Lineage tracing of sclerotome cells in amphibian reveals that multipotent somitic cells originate from lateral somitic frontier. Developmental Biology, 2019, 453, pp.11 - 18. 10.1016/j.ydbio.2019.05.009 . hal-03488174

\section{HAL Id: hal-03488174 \\ https://hal.science/hal-03488174}

Submitted on 20 Dec 2021

HAL is a multi-disciplinary open access archive for the deposit and dissemination of scientific research documents, whether they are published or not. The documents may come from teaching and research institutions in France or abroad, or from public or private research centers.
L'archive ouverte pluridisciplinaire HAL, est destinée au dépôt et à la diffusion de documents scientifiques de niveau recherche, publiés ou non, émanant des établissements d'enseignement et de recherche français ou étrangers, des laboratoires publics ou privés.

\section{(c) (1) $\$$}

Distributed under a Creative Commons Attribution - NonCommercial| 4.0 International 


\section{LINEAGE TRACING OF SCLEROTOME CELLS IN AMPHIBIAN REVEALS THAT SOMITIC MULTIPOTENT CELLS ORIGINATE FROM LATERAL SOMITIC FRONTIER}

\section{Bruno Della Gaspera ${ }^{1 *}$, Alice Mateus $^{1}$, Yannick Andéol ${ }^{2}$, Laure Weill ${ }^{1}$, Frédéric Charbonnier $^{1}$ and Christophe Chanoine ${ }^{1 *}$}

1- UMR INSERM 1124, Université de Paris, Faculté des sciences biomédicales et fondamentales, 45 rue des Saints-Pères, F-75270 Paris Cedex 06, France. Tel/Fax : 01 42862119.

2- Equipe UR6 «Enzymologie de l'ARN », Sorbonne Université, Faculté des Sciences et Technologies, 9 quai St Bernard, 75251 Paris Cedex 05, France.

* Correspondence to: B. della Gaspera or C. Chanoine, UMR INSERM 1124, Université de Paris, Faculté des sciences biomédicales et fondamentales, 45 rue des Saints-Pères, F-75270 Paris Cedex 06, France. Tel/Fax: $01 \quad 42 \quad 86 \quad 21$ 19. E-mail: bruno.dellagaspera@parisdescartes.fr or christophe.chanoine@parisdescartes.fr 


\begin{abstract}
The two somite compartments, dorso-lateral dermomyotome and medio-ventral sclerotome are major vertebrate novelties, but little is known about their evolutionary origin. We determined that sclerotome cells in Xenopus come from lateral somitic frontier (LSF) by lineage tracing, ablation experiments and histological analysis. We identified Twistl as marker of migrating sclerotome progenitors in two amphibians, Xenopus and axolotl. From these results, three conclusions can be drawn. First, LSF is made up of multipotent somitic cells (MSCs) since LSF gives rise to sclerotome but also to dermomytome as already shown in Xenopus. Second, the basic scheme of somite compartmentalization is conserved from cephalochordates to anamniotes since in both cases, lateral cells envelop dorsally and ventrally the ancestral myotome, suggesting that lateral MSCs should already exist in cephalochordates. Third, the transition from anamniote to amniote vertebrates is characterized by extension of the MSCs domain to the entire somite at the expense of ancestral myotome since amniote somite is a naive tissue that subdivides into sclerotome and dermomyotome. Like neural crest pluripotent cells, MSCs are at the origin of major vertebrate novelties, namely hypaxial region of the somite, dermomyotome and sclerotome compartments. Hence, change in MSCs properties and location is involved in somite evolution.
\end{abstract}




\section{INTRODUCTION}

Somites are embryonic transitory structures located in dorsal paraxial mesoderm on both side of neural tube and notochord (Bothe et al, 2007; Sambasivan and Tajbakhsh, 2007). Somites segment and differentiate in an antero-posterior direction during development. The somite subdivision into dermomyotome, myotome, and sclerotome forms the basis of the musculoskeletal system organization that gives rise to muscle (from dermomyotome and myotome), and also bone and tendon (from sclerotome). Somites are specific to Chordates and are major contributors of vertebrate evolutionary novelties. Indeed, vertebrae that gave the name of vertebrate subphylum originate from sclerotome. At the phylotypic stage (Irie and Kuratani, 2011), the most conserved stage of vertebrate development, somite compartmentalization is similar between the distinct classes of vertebrates (della Gaspera et al, 2018).

Interestingly, the initial phase of compartmentalization differs between amniotes and anamniotes suggesting that anamniote somite organisation is closest to the chordate ancestor. In amniotes, the newly formed somites are naïve structures composed of multipotent somitic cells (MSCs) that divide into dermomyotome dorsally and sclerotome ventrally (Yusuf and Brand-Saberi, 2006; Buckingham and Vincent, 2009). Next, myotome cells arising from the dermomyotome sit between dermomyotome and sclerotome. In contrast, in anamniotes, compartmentalization begins before somite formation and is organized in medio-lateral way (Devoto et al, 1996; Hinits et al, 2009; della Gaspera et al, 2012a). The ancestral myotome appears first medially from the presomitic mesoderm whereas the dermomyotome appears laterally before becoming dorsal structure (Hollway et al, 2007, della Gaspera et al, 2012b). However, the origin of sclerotome in the anamniotes is still unclear. In a primitive chordate, the cephalochordate amphioxus, the somite compartmentalization is similar to anamniote vertebrates, with an ancestral myotome positioned medially. Although the lateral area is poorly characterized, derivative sclerotome-like cells have been recently identified (Mansfield et al, 2015). Therefore, understanding the sclerotome origin in anamniotes may provide an advanced picture of the evolutionary history of somite compartmentalization. Here, we investigated the origin of sclerotome cells in amphibians and showed by lineage tracing, histological analysis, tissue ablation and gene marker studies that sclerotome cells come from the lateral somitic frontier (LSF). 


\section{MATERIALS AND METHODS}

\section{Ethics statement}

This work uses early Xenopus laevis and axolotl (Ambystoma mexicanum) embryos. All experimental procedures used in this study followed the recommendations of the "Comité National de Réflexion Ethique sur l'Expérimentation Animale' of the Ministry of Higher Education and Research and were approved by local Animal Care and Use Committees.

\section{Lineage tracing experiments and immunofluorescence}

Stage 13 embryos were injected using pulled-glass capillaries either with wheat germ agglutinin, WGA-rhodamine or -fluorescein or both (dissolved at $200 \mu \mathrm{g} / \mathrm{mL}$, Vector laboratories) to be analysed at stages 23 and 28. Single injections were performed at LSF or at medial level of presomitic mesoderm. Double injections with WGA-rhodamine and fluorescein were performed at medial and lateral regions respectively. Embryos were photographed at stage 13 and fixed in $4 \%$ formaldehyde at stage 28 . The fate of stained cells was directly analysed on $50 \mu \mathrm{m}$ trunk transverse vibratome sections or after immunofluorescence with the muscle-specific 12/101 or MF20 monoclonal antibodies used at 1:300 dilution for 1 hour (Developmental studies hybridoma bank-University of Iowa). The primary antibody was recognized by Alexa fluor donkey 488 anti-mouse secondary antibody (Life technologies) used at 1:300 dilution for 1 hour. In some cases, vibratome sections were incubated with Hoechst 33258 (Sigma) at 1:2000 dilution for 5 minutes before being analysed. Embryos were staged according to Nieuwkoop and Faber (1994), and Schreckenberg and Jacobson (1975).

\section{Whole-mount in situ hybridization and immunohistochemistry}

cDNA for whole-mount in situ hybridization (ISH) probes were prepared by RT-PCR with the following forward and reverse primers: 5'-GAGCTGGACTCCAAAATGGC-3' and 5'TGGCAACGCATGCATGCAGT-3' for Twist1, 5'-ATCCCAGCCAACGTTACCCT-3' and 5'-GAtgaAgAtgGGaGtgGAAG-3' for Paxl, 5'-ACCACATACAACGCCATGGG-3' and 5'-GTTACTTTGTGTGTCCTCCAG-3' for Pax9, 5'-AAAGATGCCACCAAGGAGGA- 
GGAAGATCGGCTCCTTAAAG-3' and 5'-ACGTTGGGAAAAGTCTGCTG-3' for FoxC2 or 5'-GACGAGCTCGACTCCAAGAT-3' and 5'-AATGGAGTGTGGGCAATGTC-3' for axolotl Twist1. PCR products were cloned into pGEM-T (Promega). cDNAs of Meox2, Tcf15, MyhE3, Mef2c and Myodl were previously described (della Gaspera et al, 2009 and 2012b). RNA probes synthesis and whole mount in situ hybridization were carried out as previously described (Harland, 1991). Following in situ hybridization and depigmentation, embryos were fixed at room temperature for 1 hour in $4 \%$ formaldehyde, $0.25 \%$ glutaraldehyde PBS (Phosphate Buffer Saline) solution before embryos were sectioned transversally. When both in situ hybridization and 12/101 immunostaining were carried out, embryos were first stained using in situ hybridization and sectioned before immunohistochemistry. The 12/101 antibody was used at 1:1000 dilution and detected with an alkaline phosphatase-conjugated anti-mouse antibody (Vector Laboratories) diluted at 1:1000 followed by reaction with BCIP (SigmaAldrich)

\section{Embryos section}

Following in situ hybridization, fixed embryos were embedded in a PBS solution with 3\% agarose, $1 \%$ porcine gelatin B (Sigma) and $0.01 \%$ glutaraldehyde. In the other cases, embryos were embedded without adding glutaraldehyde. $40 \mu \mathrm{m}$ vibratome sections were performed transversally and serially, in an orderly way from anterior to posterior side. For histological analysis, embryos sections were incubated successively with 12/101 antibody at 1:300 dilution for 1 hour, Alexa fluor donkey 488 anti-mouse secondary antibody at 1:300 dilution for 1 hour, diI (Molecular Probes) at $10 \mu \mathrm{g} / \mathrm{mL}$ or WGA-rhodamine at $20 \mu \mathrm{g} / \mathrm{mL}$ for 15 minutes and Hoechst 33258 (Sigma) at 1:2000 dilution for 5 minutes.

\section{Ablation experiments}

Dechorionated embryos were oriented and immobilized in 0.4X MMR 1\% agarose gel slits. Using sharpened needles, antero-posterior incision in the ectoderm was performed at stages 17-18 on the dorsal side of the embryo at the medial (Abl. M) or lateral level (Abl. L). Ectoderm and mesoderm were separated from each other on the lateral incision side and the superficial part of the mesoderm was removed. The sham-operated (Abl. C) embryos were treated without removing the mesoderm. The embryos were fixed at stages 28,32 or 45 . 


\section{RESULTS}

In order to highlight the fate of LSF cells specified by Meox2 expression (della Gaspera et al, 2012b and Fig. 1) during Xenopus development, we first double injected stage 13 embryos with fluorescent dyes, WGA-fluorescein (green) in the LSF and WGA-rhodamine (red) in the medial presomitic mesoderm (Fig. 1A a, b and c). At stage 28, as shown in three distinct embryos in Figure 1, cells located at the somite periphery are stained by the WGAfluorescein, suggesting that LSF migrate to these regions. Cells located to the most dorsolateral region correspond to the dermomyotome as previously showed (della Gaspera et al, 2012b) while the ventral and medial cells near the neural tube and notochord could be sclerotome cells (Fig. 1A g, h and i) (Sánchez and Sánchez, 2013). As expected (della Gaspera et al, 2012a and b), the medial-injected cells (WGA-rhodamine/red) gave rise to internal somitic cells (Fig. 1A d, e and f). Co-staining with a nuclear marker showed clearly that cells between the notochord and the myotome (Fig. 1B and C) were labeled after injection in the LSF (Fig. 1B), but never after injection in the medial presomitic mesoderm (Fig. 1C), indicating that non-muscle cells of lateral origin were present in ventral and medial region of the somites. Indirect immunofluorescence with two muscle-specific antibodies (green) either 12/101 (Fig. 1D a and a') or MF20 (Fig. 1D d and d') on embryos previously injected with WGA-rhodamine in the LSF (Fig. 1D b, e, b' and e') confirmed no colocalization of the rhodamine labelled cells with the myotome. In addition, in situ hybridization experiments revealed that Twistl (Fig. 1E a) and Paxl/Pax9 mRNAs (Fig. 1F a), two sclerotome markers (Fleming et al, 2015), were expressed in the same region. Finally, a co-staining of fluorescent LSF-derived cells with Twist1 (Fig. 1E b and c) or Pax1/Pax9 cRNA probes (Fig. 1F c and d) on serial transverse sections (Fig. 1F) identified these cells as sclerotome ones. Hence, our results suggest that cells from LSF migrate around primitive myotome dorsally and ventrally to give rise to dermomyotome and sclerotome cells.

We showed previously that LSF expresses Meox2 and Tcf15 at stage 13 (della Gaspera et al., 2012b) and two early mesoderm and somitic markers, Foxc1 and Foxc2, which are broadly expressed in the trunk mesoderm but not in the notochord. The LSF cells probably migrate medially by extension-convergence, then at stage 18 , extend into lateral somitic domain (della Gaspera et al, 2012b). The lateral somitic domain still expresses the same markers than LSF, while the ancestral myotome differentiates first medially (stage 16) and next dorso-laterally (stages 17/18) (della Gaspera et al, 2012a). To characterize molecularly 
the migrating sclerotome progenitors, we performed here in situ hybridization experiments, with the LSF markers Meox2 and Tcf15 and sclerotome-expressed genes, Foxc1, Foxc2 and Twistl (Fleming et al, 2015) in comparison with myotome marker Myodl.

Twist 1 was expressed at stage 20 in the lateral somitic domain and this expression was stronger in cells bordering the myotome (Fig. 2A). In the following stages, during myotome growth, dermomyotome progenitors migrate dorsally and continued to express LSF markers and Twist1 (Fig. 2A). While dermomyotome maturation, the expression of Meox2, Tcf15 and Twist 1 fell, and Foxcl and Foxc2 expressions were restricted to hypaxial and epaxial regions (Fig. 2A). Concerning the sclerotome cells, only Twistl was expressed in the cell layers that were located ventrally and medially at stage 26. Foxcl and Foxc2 mRNAs started to accumulate in the sclerotome cells only at stage 34 (Fig. 2A). Considering that somites differentiate in an antero-posterior way, we analysed Twist 1 expression in transverse sections from posterior to anterior direction at stage 28 (Fig. 2B). Twistl expression domain shifted over somite differentiation, from lateral region caudally, to medial location anteriorly (Fig. 2B a to f). In the same way, histological analysis in transverse sections, with myotome marker and diI to mark all cells, from posterior to anterior direction, allowed to easily visualize a nonmuscle cells population which seems to migrate ventrally from lateral to medial region (Fig. $2 \mathrm{C})$. In the less differentiated somite, at posterior region, these cells were located laterally (Fig. 2C). These cells seem to migrate between the myotome and endoderm at slightly more anterior region and, between the myotome and the notochord, at the most anterior region (Fig. 2C). We equally observed these seemingly moving cells (Fig. 3A), and shift of Twist1 expression from lateral to medial domain (Fig. 3B), over time from stages 18 to 25, at the anterior trunk level. Altogether, these results suggest that lateral Twist1 expressing cells migrate ventrally to give rise to sclerotome.

We next followed experimentally the sclerotome progenitors expressing Twist 1 from lateral to medial somite side. LSF-injected cells at stage 13 give rise to lateral somitic domain at stage 18 (della Gaspera et al, 2012b) which express Twist1 (Fig. 3B). We fixed LSF-injected embryos at stage 22/23, which were also stained with myotome marker (Fig. 3C) or with Twist1 ISH-probe (Fig. 3D) on the same slides. We observed a co-localization of the tracer with Twist1 expressing cells in the lateral to medial direction (Fig. 3D) indicating that these cells move ventrally from lateral to medial side of the somite (Fig. 3C and D). To confirm experimentally the origin of sclerotome cells, we proceeded to the ablation of lateral somitic domain at stage 17, when Twistl begin to be expressed, and showed that the absence of these cells dramatically affected sclerotome formation since no Twistl expression at stage 28 was 
detected (Fig. 3E) while immunohistochemistry with 12/101 antibody indicated that the myotome was faintly affected. Neither the sham-operated embryos, nor the ablation of medial somite leaded to a decrease in Twistl expression. We already showed that ablation of LSF leads to absence of dermomyotome and particularly to Pax3 expression at hypaxial region (della Gaspera et al, 2012b). Here, we confirmed that ablation of LSF prevented the development of hypaxial muscles derived from somite (Fig. 3F). Since the syndetome, which give rise to tendons and ligaments is derived from sclerotome in amniotes and anamniotes (Brent et al, 2003; Bricard et al, 2014), we also analyzed the expression of Mef2c, a syndetome marker in Xenopus (della Gaspera et al, 2009) and probably in mice (Edmondson et al, 1994). Mef2c expression was strongly decreased after the ablation of lateral somitic domain (Fig. 3G). Altogether, the co-staining of the tracer with Twistl-expresssing cells and the LSF ablation experiments confirms that the sclerotome/syndetome originates from lateral somitic domain. Moreover, hypaxial muscles stems also from lateral somitic domain.

To ensure that the lateral origin of sclerotome cells is a general anamniote feature, we then performed whole-mounted hybridization for Twist 1 on the urodelan amphibian, axolotl, at stage 31 (Fig. 4A) and compared to myotome staining by 12/101 antibody (Fig. 4B). Twist1 expression was also analyzed in transverse sections from posterior to anterior direction as somite differentiates (Fig. 4A and B, a to g). As in Xenopus embryos, Twist1 was detected in non-muscle cells which seem to migrate ventrally from lateral region to medial region (Fig. 4A and 4B). As in Xenopus embryos, in the less differentiated somite at posterior level, Twist1 expressing cells were located laterally. At slightly more anterior level, Twist1 expressing cells seem to migrate between the myotome and endoderm (Fig. 4A and B) before migrating between myotome and notochord. At the same time, Twist1 mRNA level also decreased sharply, in contrast to Xenopus. Despite this difference, these results strongly suggest that the sclerotome cells have also a lateral origin in axolotl. 


\section{DISCUSSION}

The combination of lineage tracing, histological analysis, ablation experiments, and expression markers studies shows that sclerotome cells originate from LSF at early neurulation in Xenopus. Twist1 marks ventrally the migrating sclerotome cells and Twist1 expression in axolotl confirms that the lateral origin of sclerotome cells is a general anamniote trait. Moreover, LSF is made up of MSCs since (1) early somite markers as Meox2 and Tcf15 are strongly expressed at LSF (della Gaspera et al, 2012b) and (2) both sclerotome and dermomyotome (della Gaspera et al, 2012b) derive from LSF.

Twist 1 marks ventrally the migrating sclerotome cells but is not restricted to these cells in somites. In amniotes, Twistl has been shown expressed in whole undifferentiated somites before to be restricted to the sclerotome (Füchtbauer, 1995; Gitelman, 1997). In Xenopus, we show here that Twistl is first expressed in the lateral somitic domain and next both in the migrating dorsal and ventral cells until stage 23-24, before to be restricted to the sclerotome at later stages (Fig. 2A). The lateral somitic domain and next, the dorsal part of the somite that gives rise to the functional dermomyotome at stage 28 , also express other early patterning somite genes like Foxc1, Foxc2, Meox2 and Tcf15 until stage 23-24. It has been shown that these somite patterning genes could participate to the dermomyotome but also to the sclerotome formation (Kume et al, 2001; Mankoo et al, 2003; Wilson-Rawls et al, 2004; Linker et al, 2005). Hence, although the sclerotome precursors expressing Twist 1 seem to take the ventral route to form the sclerotome medially, we cannot exclude that some dorsal sclerotome cells come from the dorsal route. Moreover, in zebrafish, a dorsal sclerotome domain with specific markers has been recently characterized (Ma et al, 2018).

The discovery of MSCs at LSF in addition to the knowledge about ancestral myotome and dermomyotome provides a more precise description of somite compartmentalization in Xenopus (della Gaspera et al, 2012a and b), making it easier comparisons between chordate species, and allows reconstructing the evolutionary history model of somite compartmentalization (Fig. 4D). MSCs should be already present in amphioxus since lateral somite cells, like in Xenopus, migrate dorsally and ventrally in order to give rise to both external cells and sclerotome-like cells respectively (Mansfield et al, 2015). The transition 
from cephalochordates to vertebrates is characterized by appearance of new somitic compartments, namely the hypaxial region of dermomyotome, the dermomyotome itself and the sclerotome. Our results show that all these new somite novelties in vertebrates derive from MSCs. MSCs or MSC-daughter cells evolution could be related to the modification of their cell potency state, allowing MSCs to acquire new cell identities and/or to redeploy preexisting genetic program. Indeed, the new set of genes inherited from the double whole genome duplication ( $2 \mathrm{R}$ hypothesis) that took place during this evolutionary period (Panopoulou and Poustka, 2005), could participate to the evolution of MSCs and somite novelties (Shimeld and Holland, 2000; Furlong and Holland, 2002). It is the MSCs location that changes at the transition from anamniote to amniote vertebrates. We previously proposed that the transition from anamniotes to amniotes is associated to the loss of ancestral myotome (della Gaspera et al, 2012a). Hence, the transition from anamniotes to amniotes is characterized by global extension of MSCs to the entire somite at the expense of ancestral myotome (Fig. 4D). In amniotes, the whole newly formed somite is a naïve structure that expresses the same markers as Xenopus MSCs at LSF (Chal and Pourquié, 2017, Nakajima et al, 2018). The evolutionary advantages of the MSCs domain extension remain to be determined but it could be related to the appearance of a larger sclerotome and facilitating the formation of its derivatives. It is well known that the muscle development begins earlier in anamniotes than in amniotes probably because the water tadpole must quickly find its own feeding. In Xenopus somite, we identified three successive myogenic waves during embryogenesis, on the basis of myogenic regulatory factors expression (della Gaspera et al, 2012a). The two first ones give rise to the primary myotome, formed by mononucleated fibers until stage 45 (Kiełbówna and Daczewska, 2005). The third one participates to the myotome growth. More precisely, the first -medial and lateral- myogenic wave is at the origin of the ancestral myotome, which disappeared per se in amniotes. The second wave, at the hypaxial and epaxial lips of the dermomyotome, is similar to those observed at the beginning of amniote myogenesis, with strong expression of Myf5 and Myog. Hence, we hypothesized that the first -medial and lateral- myogenic wave was lost, at least in mice (della Gaspera et al, 2012a). However, it seems that the remnants of first wave could still be present in amniotes, as in the chick (Fig. 4D). Indeed, muscle pioneer cells observed precociously in medial somite during chick myotome formation seem to be the remnant of the first medial myogenic wave (Kahane et al, 1998). Moreover, amniote dermomyotome can generate the primary myotome not only from its epaxial and hypaxial borders but also from its anterior and posterior borders (Gros et al, 2004). Although epaxial and hypaxial myogenesis presents similarities between 
Xenopus and amniotes, as explained above, myogenic cells arising from anterior and posterior borders have until now no equivalents in Xenopus. One hypothesis is that the first lateral wave in Xenopus could evolve to give rise to these anterior and posterior populations. Therefore, further studies are needed to find whether specific features are shared between these two myogenic populations.

Our results point out that change in MSCs properties and location could partly explain both the transition from cephalochordates to vertebrates and from anamniote to amniote vertebrates, underlining the particular role of some kind of multipotent embryonic cells during vertebrate evolution. In the same way, neural crest cells are vertebrate-specific and pluripotent cells that give rise to numerous cell types (Buitrago-Delgado et al, 2015). Neural crests also contribute to the major vertebrate novelties like MSCs do (Shimeld and Holland, 2000). This raises the question, how and to what extent, acquisition or modification of the cell potency state in a specific cell type could be essential to vertebrate evolution.

\section{Acknowledgments:}

We thank Dr Anne Simon for providing some reagents.

\section{Competing interests:}

The authors declare no competing or financial interests.

\section{Funding:}

This work was supported by INSERM (Institut National de la Santé et de la Recherche Médicale) and Université Paris Descartes. This research did not receive any specific grant from funding agencies in the public, commercial, or not-for-profit sectors. 


\section{REFERENCES}

Bothe, I., Ahmed, M.U., Winterbottom, F.L., von Scheven, G., Dietrich, S., 2007. Extrinsic versus intrinsic cues in avian paraxial mesoderm patterning and differentiation. Dev. Dyn. 236, 2397-2409. https://doi.org/10.1002/dvdy.21241

Brent, A.E., Schweitzer, R., Tabin, C.J., 2003. A somitic compartment of tendon progenitors. Cell 113, 235-48. https://doi.org/10.1016/S0092-8674(03)00268-X

Bricard, Y., Rallière, C., Lebret, V., Lefevre, F., Rescan, P.-Y., 2014. Early fish myoseptal cells: insights from the trout and relationships with amniote axial tenocytes. PLoS One 9, e91876. https://doi.org/10.1371/journal.pone.0091876

Brunet, T., Lauri, A., Arendt, D., 2015. Did the notochord evolve from an ancient axial muscle? The axochord hypothesis. Bioessays 37, 836-50. https://doi.org/10.1002/bies.201500027

Buckingham, M., Vincent, S.D., 2009. Distinct and dynamic myogenic populations in the vertebrate embryo. Curr. Opin. Genet. Dev. 19, 444-53. https://doi.org/10.1016/j.gde.2009.08.001

Buitrago-Delgado, E., Nordin, K., Rao, A., Geary, L., LaBonne, C., 2015. NEURODEVELOPMENT. Shared regulatory programs suggest retention of blastulastage potential in neural crest cells. Science 348, 1332-5. https://doi.org/10.1126/science.aaa3655

Chal, J., Pourquié, O., 2017. Making muscle: skeletal myogenesis in vivo and in vitro. Development 144, 2104-2122. https://doi.org/10.1242/dev.151035

Della Gaspera, B., Armand, A.-S., Lecolle, S., Charbonnier, F., Chanoine, C., 2012. Mef2d acts upstream of muscle identity genes and couples lateral myogenesis to dermomyotome formation in Xenopus laevis. PLoS One 7, e52359. https://doi.org/10.1371/journal.pone.0052359

Della Gaspera, B., Armand, A.-S., Sequeira, I., Chesneau, A., Mazabraud, A., Lécolle, S., Charbonnier, F., Chanoine, C., 2012. Myogenic waves and myogenic programs during Xenopus embryonic myogenesis. Dev. Dyn. 241, 995-1007. https://doi.org/10.1002/dvdy.23780

Della Gaspera, B., Armand, A.-S., Sequeira, I., Lecolle, S., Gallien, C.L., Charbonnier, F., Chanoine, C., 2009. The Xenopus MEF2 gene family: evidence of a role for XMEF2C in larval tendon development. Dev. Biol. 328, 392-402. https://doi.org/10.1016/j.ydbio.2009.01.039

Della Gaspera, B., Chesneau, A., Weill, L., Charbonnier, F., Chanoine, C., 2018. Xenopus SOX5 enhances myogenic transcription indirectly through transrepression. Dev. Biol. 442, 262-275. https://doi.org/10.1016/j.ydbio.2018.07.025 
Devoto, S.H., Melançon, E., Eisen, J.S., Westerfield, M., 1996. Identification of separate slow and fast muscle precursor cells in vivo, prior to somite formation. Development 122, 3371-80. https://doi.org/10.1103/PhysRevB.61.16956

Edmondson, D.G., Lyons, G.E., Martin, J.F., Olson, E.N., 1994. Mef2 gene expression marks the cardiac and skeletal muscle lineages during mouse embryogenesis. Development $120,1251-63$.

Fleming, A., Kishida, M.G., Kimmel, C.B., Keynes, R.J., 2015. Building the backbone: the development and evolution of vertebral patterning. Development 142, 1733-44. https://doi.org/10.1242/dev.118950

Füchtbauer, E. -m, 1995. Expression of M-twist during postimplantation development of the mouse. Dev. Dyn. https://doi.org/10.1002/aja.1002040309

Furlong, R.F., Holland, P.W.H., 2002. Were vertebrates octoploid? Philos. Trans. R. Soc. Lond. B. Biol. Sci. 357, 531-44. https://doi.org/10.1098/rstb.2001.1035

Gitelman, I., 1997. Twist Protein in Mouse Embryogenesis. Dev. Biol. 189, 205-214. https://doi.org/10.1006/dbio.1997.8614

Gros, J., Scaal, M., Marcelle, C., 2004. A two-Step mechanism for myotome formation in chick. Dev. Cell. 6, 875-882. https://doi.org/10.1016/j.devcel.2004.05.006

Harland, R.M., 1991. In situ hybridization: an improved whole-mount method for Xenopus embryos. Methods Cell Biol. 36, 685-695.

Hinits, Y., Osborn, D.P.S., Hughes, S.M., 2009. Differential requirements for myogenic regulatory factors distinguish medial and lateral somitic, cranial and fin muscle fibre populations. Development 136, 403-14. https://doi.org/10.1242/dev.028019

Hollway, G.E., Bryson-Richardson, R.J., Berger, S., Cole, N.J., Hall, T.E., Currie, P.D., 2007. Whole-somite rotation generates muscle progenitor cell compartments in the developing zebrafish embryo. Dev. Cell 12, 207-19. https://doi.org/10.1016/j.devcel.2007.01.001

Irie, N., Kuratani, S., 2011. Comparative transcriptome analysis reveals vertebrate phylotypic period during organogenesis. Nat. Commun. 2, 248. https://doi.org/10.1038/ncomms1248

Kahane, N., Cinnamon, Y., Kalcheim, C., 1998. The origin and fate of pioneer myotomal cells in the avian embryo. Mech. Dev. 74, 59-73. https://doi.org/10.1016/S09254773(98)00066-5

Kiełbówna, L., Daczewska, M., 2005. The origin of syncytial muscle fibres in the myotomes of Xenopus laevis - A revision. Folia Biol. (Krakow). 53, 39-44. https://doi.org/10.3409/1734916054663401

Kume, T., 2001. The murine winged helix transcription factors, Foxc1 and Foxc2, are both required for cardiovascular development and somitogenesis. Genes Dev. 15, 2470-2482. https://doi.org/10.1101/gad.907301 
Linker, C., 2005. Beta-catenin-dependent Wnt signalling controls the epithelial organisation of somites through the activation of paraxis. Development 132, 3895-3905.

https://doi.org/10.1242/dev.01961

Ma, R.C., Jacobs, C.T., Sharma, P., Kocha, K.M., Huang, P., 2018. Stereotypic generation of axial tenocytes from bipartite sclerotome domains in zebrafish. PLOS Genet. 14, e1007775. https://doi.org/10.1371/journal.pgen.1007775

Mankoo, B.S., Skuntz, S., Harrigan, I., Grigorieva, E., Candia, A., Wright, C.V.E., Arnheiter, H., Pachnis, V., 2003. The concerted action of Meox homeobox genes is required upstream of genetic pathways essential for the formation, patterning and differentiation of somites. Development 130, 4655-4664. https://doi.org/10.1242/dev.00687

Mansfield, J.H., Haller, E., Holland, N.D., Brent, A.E., 2015. Development of somites and their derivatives in amphioxus, and implications for the evolution of vertebrate somites. Evodevo 6, 21. https://doi.org/10.1186/s13227-015-0007-5

Nakajima, T., Shibata, M., Nishio, M., Nagata, S., Alev, C., Sakurai, H., Toguchida, J., Ikeya, M., 2018. Modeling human somite development and fibrodysplasia ossificans progressiva with induced pluripotent stem cells. Development 145, dev165431. https://doi.org/10.1242/dev.165431

Nieuwkoop, P.D. and Faber, J., 1994. Normal table of Xenopus laevis (Daudin).

Panopoulou, G., Poustka, A.J., 2005. Timing and mechanism of ancient vertebrate genome duplications -- the adventure of a hypothesis. Trends Genet. 21, 559-67. https://doi.org/10.1016/j.tig.2005.08.004

Sambasivan, R., Tajbakhsh, S., 2007. Skeletal muscle stem cell birth and properties. Semin. Cell Dev. Biol. 18, 870-82. https://doi.org/10.1016/j.semcdb.2007.09.013

Sánchez, R.S., Sánchez, S.S., 2013. Characterization of pax1, pax9, and uncx sclerotomal genes during Xenopus laevis embryogenesis. Dev. Dyn. 242, 572-9. https://doi.org/10.1002/dvdy.23945

Schreckenberg, G.M., Jacobson, A.G., 1975. Normal stages of development of the axolotl. Ambystoma mexicanum. Dev. Biol. 42, 391-400. https://doi.org/10.1016/00121606(75)90343-7

Shimeld, S.M., Holland, P.W., 2000. Vertebrate innovations. Proc. Natl. Acad. Sci. U. S. A. 97, 4449-52. https://doi.org/10.1073/pnas.97.9.4449

Wilson-Rawls, J., Rhee, J.M., Rawls, A., 2004. Paraxis Is a Basic Helix-Loop-Helix Protein That Positively Regulates Transcription through Binding to Specific E-box Elements. J. Biol. Chem. 279, 37685-37692. https://doi.org/10.1074/jbc.M401319200

Yusuf, F., Brand-Saberi, B., 2006. The eventful somite: patterning, fate determination and cell division in the somite. Anat. Embryol. (Berl). 211 Suppl, 21-30.

https://doi.org/10.1007/s00429-006-0119-8 
Figure 1. Sclerotome cells originate from lateral somitic frontier (A) Scheme of the experimental procedure: lineage tracing experiments with WGA-rhodamine injected in the medial segmental plate and with WGA-fluorescein injected in the Meox2 expression domain at LSF. a to c: Results for three embryos double injected at stage 13. d to i: Transverse section at stage 28. WGA-rhodamine (d, e, f), WGA-fluorescein (g, h, i), merge (j, k, l). Dash lines indicate the position of bilateral symmetry plane. Horizontal lines define the limit between anterior and trunk regions. Anterior side on the top. Nc, notochord. Nt, neural tube. (B) Scheme of the experimental procedure: lineage tracing experiments with WGAfluorescein injected in the Meox2 expression domain at LSF. Fixed embryos were stained with Hoechst 33258 nucleus marker. Transverse section was performed at stage 28. Blue Hoechst 33258 nucleus marker (a), green WGA-fluorescein (b), merge (c). Arrows designs cells lining the notochord and muscle cells. (C) Scheme of the experimental procedure: lineage tracing experiments with WGA-rhodamine injected in the medial segmental plate. Fixed embryos were stained with Hoechst 33258 nucleus marker and 12/101 specific antibody for muscle cells. Transverse section were performed at stage 28. Blue nuclear staining alone (a) with red WGA-rhodamine (b), with green muscle cells (c), merge (d). (D) Scheme of the experimental procedure: embryos were injected in LSF with WGA-rhodamine at stage 13 and then transverse trunk sections at stage 28 were submitted to indirect immunofluorescence with 12/101 (a) or MF20 antibodies (d). b and e, WGA-rhodamine staining; c and f, merge. Rectangle dotted line designs the area magnification at the right side (a', b', c' and d', e', f'). (E) Scheme of the experimental procedure: embryos were injected in LSF with WGAfluorescein (green) and then submitted to ISH with Twist1 probe or directly observed. a, Twist 1 expression analysis in an uninjected embryo; b-c, serial sections submitted to ISH with Twist 1 probe (b) or directly observed (c). (F) Scheme of the experimental procedure: Paxl plus Pax9 expression analysis in an uninjected embryo (a). Serial sections of an embryo injected in LSF with WGA-rhodamine (red) submitted to ISH with Paxl and Pax9 probes (c) compared to ISH negative control (b) or directly observed (d). Arrows design co-staining areas. Scale bars: $100 \mu \mathrm{m}$.

Figure 2. Twist1 is expressed in seemingly migrating sclerotome cells. (A) Scheme of the experimental procedure: expression of the somite patterning genes Meox2, Tcf15, Foxc1, Foxc2 and Twist 1 in comparison to Myodl on trunk transverse sections between stages 20 and 34. The analyzed gene is indicated at the bottom right of each picture. Arrows design the 
stained sclerotome. (B) Postero-anterior expression of Twist1 at stage 28 on transverse section (a to f). (C) Somitic ventral migrating cells (arrows) on postero-anterior transverse sections (a to e). Orderly serial transverse sections stained by myotome marker (12/101 antibody, green), membrane lipophilic diI (red), and Hoechst 33258 nucleus marker (blue). DiI is used here to stain all cells. Rectangle dotted line designs the area magnification at the right side of each section (a' to e'). Scale bars: $100 \mu \mathrm{m}$.

Figure 3. The WGA tracer co-localizes with Twist1-expressing cells in the ventral route (A) Scheme of the experimental procedure: postero-anterior sections of embryos (a to d) at stages 18, 21, 23 and 25 were stained by a myotome marker (12/101 antibody, green), WGArodhamine (red), and Hoechst 33258 nucleus marker (blue). WGA is used here to mark all cells and to better visualize the notochord contour. Brackets design somitic ventral migrating cells. Rectangle dotted line designs the area magnification at the bottom (stage 18) or at the right side (stages 21, 23 and 25) of each section (a' to d'). Scale bars: $100 \mu \mathrm{m}$. (B) Posteroanterior expression of Twistl at stage 18,21, 23 and 25 on transverse sections (a to d). (C) Scheme of the experimental procedure: lineage tracing experiments with WGA-rhodamine (red) injected in the Meox2 expression domain at stage 13, fixed and sectioned at stage 22/23, then sections were stained with a myotome marker (12/101 antibody, green) and Hoechst 33258 nucleus marker. (D) Scheme of the experimental procedure: lineage tracing experiments with WGA-rhodamine (red) injected in the Meox2 expression domain at stage 13, fixed and sectioned at stage 22/23, then slides were stained with Hoechst 33258 nucleus marker. The same slides were next submitted to in situ hybridization with Twist 1 probe to evaluate co-staining of WGA tracer with Twist 1 expression. Arrows design cells labelled by WGA-rhodamine. (E), (F) and (G). Ablation of lateral somitic domain prevents sclerotome and hypaxial muscles formation. Scheme of the experimental procedure: ablation experiments of the lateral somitic domain at stage 17. Embryos were fixed and analyzed for Twistl (E), $\operatorname{MyhE3}(\mathrm{F})$ and $\operatorname{Mef2c}(\mathrm{G})$ expressions (arrows) and in comparison with 12/101 staining in E. Abl. C, sham-operated embryos. Abl. M, medial domain was removed. Abl. L, lateral domain was removed. For statistical analysis, number of embryos is as follows: same expression, faint decreased, strong decreased. Kruskal-Wallis test and Dunn's multiple comparisons test revealed significant difference between Abl. L with Abl. C or Abl. M, for both Twistl $\mathrm{p}<$ 0.0001, (Abl. C 13, 2, 0; Abl. M 13, 3, 0; Abl. L 0, 2, 13), and Mef2c p< 0.0001, (Abl. C 24, 0, 0; Abl. M 15, 6, 0; Abl. L 3, 0, 16) expressions. Mann-Whitney test revealed significant 
difference between Abl. L with Abl. C for MyhE3 expression p<0.0001 (Abl. C 15, 0, 0; Abl. $\mathrm{L} 0,5,10)$

Figure 4. Twist1 marks lateral migrating sclerotome cells in axolotl. Scheme of experimental procedure: Postero-anterior transverse sections (a to g) of axolotl embryos at stage 31 after whole mount in situ hybridization with Twist1 (A) or immunohistochemistry with 12/101 antibody (B). Arrows design migrating sclerotome progenitors. Rectangle dotted line designs the area magnification at the bottom of each panel (A and B, a' to g'). (C) Schematic representation of somite compartmentalization in Xenopus. MSC domain is located at LSF at early neurulation (stage 13). Lateral Myodl expression domain could overlap the MSC domain. At mid-neurulation (stage 17/18), differentiation of lateral myotome is initiated and early markers of dermomyotome and sclerotome like Pax3 (della Gaspera et al, 2012b) and Twistl begin to be expressed. At stage 22 lateral cells migrate dorsally to give rise the dermomyotome. Next, sclerotome progenitors expressing Twist1 migrate ventrally to give rise to the sclerotome located medially at stage 28. (D) Evolution of somite compartmentalization based on axochord hypothesis. The axochord hypothesis (Brunet et al, 2015) proposes that the notochord evolves from a ventromedian muscle (the axochord in annelids) present in Urbilateria, the last common ancestor of bilaterian animals, and suggests that transverse muscles attached to it, could give rise to the ancestral myotome in cephalochordates. The origin of MSCs in Urbilateria is unknown. MSCs probably already exist in cephalochordates. The transition from anamniotes to amniotes is characterized by extension of MSCs domain at the expense of ancestral myotome. The chordate dorso-ventral axis is inverted compared with Urbilateria. VM, ventromedian muscle; TM, transverse muscle; M, medial somite; L, lateral somite. 


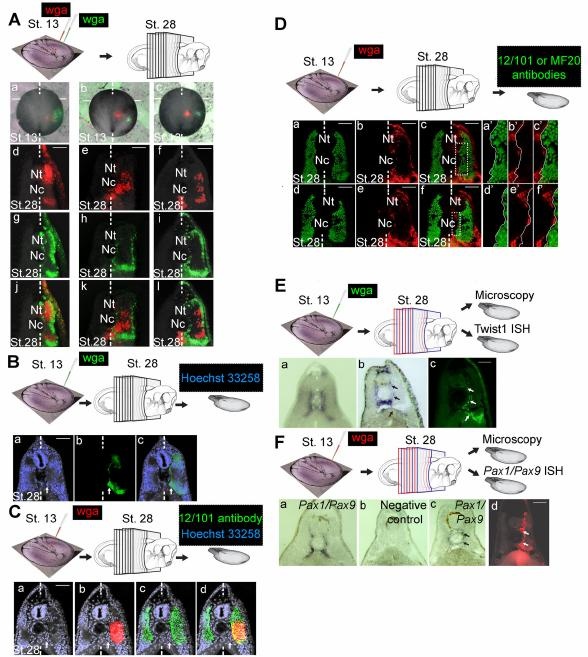


$\begin{array}{llllll}\text { A } & \text { St. } 20 & \text { st. } 22 & \text { St. } 26 & \text { St. } 30 & \text { St. } 34\end{array}$

Whole

Mount -

ISH

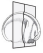

st. 22

Myod 1

St. 26

Myod1 Myod1

St. 26

St. 30

St. 34

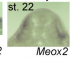

st. 22

\section{St. 26}

Meax2

St. 30

Meox2

St. 34

TCr15 TCf15

Tcf15

St. 20

Foxe1

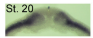

Foxc2

St.

Foxc2

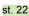

Foxc2

St. 26

Foxe1

st. 22

St. 26

St. 30

Foxc1

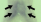

Foxc1

St. 34

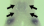

Foxc2 Foxc2

St. $30 \quad$ St. 34

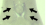

Twist1

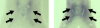
Twist1 Twist1
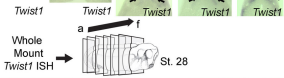

a Twist1 b Twist $\mathrm{c}$ Twist $\mathrm{d}$ Twist1 e Twist $\mathrm{f}$ Twist1

C

$\mathrm{s}$

St. 28

a

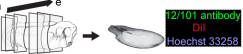

a
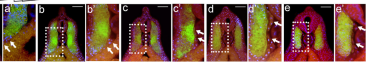
$A_{\mathrm{a}}$

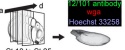

St.18 bo St.26
B

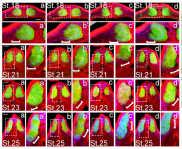

C
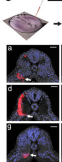

E

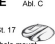

Whole mount

Twist ISH st. 28

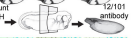

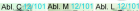

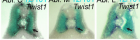

G Abl C

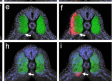

Abl $M$

AbI L
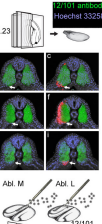

$\rightarrow \mathrm{P}$

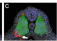

5t.17 Whole mount

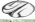

$\rightarrow$ Mer2c 15H

Abl. $M$

Cantral side Merac Contral side
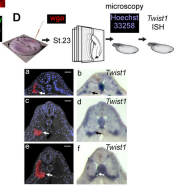

F

Abl C

Abl. L

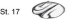

$1, \ldots$

St. 17

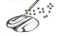

Whale mount

$\rightarrow$ Myte3 ISH at St. 45

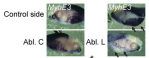

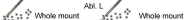

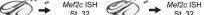

St. 32

Marac Cander sido

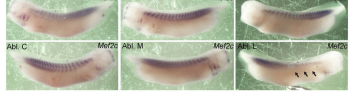




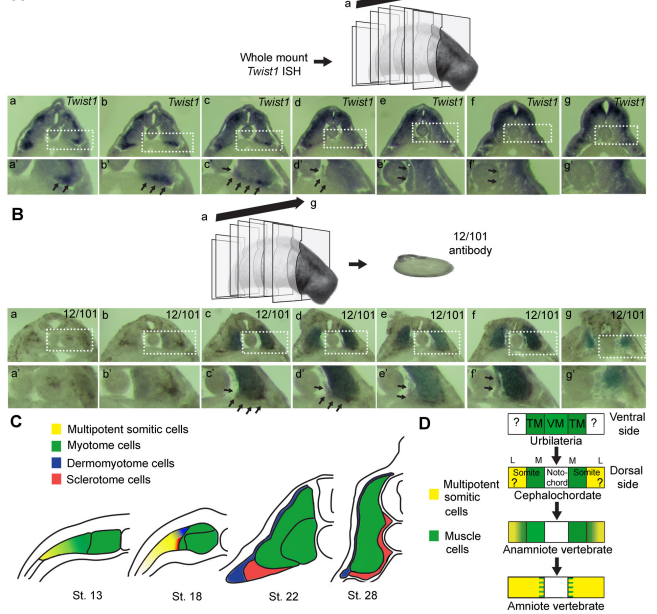

